\title{
VENDERAM MEU FUTURO: CRISE E A NOVA GERAÇÃO
}

\author{
MY FUTURE HAS BEEN SOLD: CRISIS AND THE NEW GENERATION
}

\section{Paulo Cesar Motta \\ Monica Zaidan Gomes}

Paula Valente

\section{RESUMO}

Este trabalho conjectura uma geração nascente no Brasil em meio a um cenário de turbulência econômica, decorrente particularmente da crise dos Estados Unidos. 0 método compõe-se de dois estudos distintos. 0 primeiro estudo explora a validade das memórias coletivas brasileiras em relação a eventos históricos, através de um levantamento efetuado em amostra de 572 respondentes. 0 segundo levanta possíveis experiências negativas relacionadas à crise, tendo por base valores obtidos de fontes bibliográficas. Nos resultados, foram identificadas 14 principais experiências negativas, classificadas em quatro grupos: Aversão Ao Risco, Proteção Governamental, Restrição de Consumo e Senso de Propósito. 0 trabalho conclui com proposições sobre o estilo de vida e consumo familiar, tais como valorização do consumo coletivo, substituição do prazer material pelo de maior contato humano, recuperação da cultura do "ser" em detrimento da cultura do "ter" e práticas empresariais éticas, a fim de obter reciprocidade no mercado.

Palavras-chave: Gerações históricas. Coortes. Crise. Nova geração.

\begin{abstract}
This paper addresses the issue a rising generation in the midst of economic upheaval, particularly due to the crisis in the United States. The method consists of two separate studies. The first one explores the validity of the Brazilian collective memories for historical events, through a survey carried out in a sample of 572 respondents. The second raises possible negative experiences related to the crisis, based on values obtained from literature sources. In the results, were identified 14 major negative experiences classified into four groups: Risk Aversion, Government Protection, Restrained Consumption and Sense of Purpose. The paper concludes with propositions about lifestyle and household consumption, such as the increase of collective consumption, replacement of material pleasure by more human contact, rescue of the culture of "being" rather than the culture of "having" and ethical business practices in order to obtain reciprocity in the marketplace.
\end{abstract}

Keywords: Historical generations. Cohorts. Crisis. New generation. 


\section{INTRODUÇÃO}

A capa de uma revista (THE ECONOMIST, 2009) expõe uma grossa corrente de ferro, presa por uma das suas extremidades a uma grande bola, semelhante às que impediam no passado a fuga de prisioneiros e, por outra, à perna de um bebê em posição de engatinhamento. A figura tanto simboliza o ônus que uma geração nascente herda da geração precedente quanto insere a atual crise econômica mundial na perspectiva geracional.

Embora cada país absorva valores específicos de seu momento histórico, o fenômeno geracional guarda semelhanças entre culturas, particularmente quanto aos efeitos de uma crise de ampla repercussão. Assim, crises em países presentes acentuadamente no cenário mundial tendem a afetar outros países, de modo que se não se supõe imunidade econômica, também não se supõe imunidade geracional.

Este trabalho conjectura uma geração nascente no Brasil em meio a um cenário de turbulência econômica, decorrente particularmente da crise dos Estados Unidos. Admite que os valores vivenciados e compartilhados naquele país, em ambiente de turbulências econômicas e sociais, possam repercutir nas gerações brasileiras, particularmente na geração em formação. Segue, ainda, como premissa, o que já foi assinalado em estudo anterior (MOTTA, ROSSI e SCHEWE, 2002) que os valores de gerações americanas têm inspirado valores para gerações no Brasil, tendo sido ressaltado, entretanto, que essa ocorrência se dá com um hiato temporal.

\section{O ESTUDO DAS GERAÇÕES E COORTES HISTÓRICOS}

O estudo das gerações atrai diversas áreas do conhecimento desde que levantado por seu propulsor, Mannheim, em 1928 (MANNHEIM, 1928). Permeia disciplinas que perseguem o entendimento do comportamento social, como a educação, a ciência política, a sociologia, além da gestão de marketing (MOTTA e SCHEWE, 2008; MEREDITH, SCHEWE e KARLOVICH, 2002). Como normalmente uma geração se forma reagindo aos valores da precedente, julgase que se entende melhor por essa via as mudanças sociais. Por causa disso, diversas disciplinas testemunham esse entendimento como uma ferramenta que descortina o futuro (RILEY, 1973; CUTLER, 1977; RENTZ e REYNOLDS, 1991; RENTZ, REYNOLDS e STOUT, 1983; RODGERS, 1982; GLENN, 2005).

Trabalho seminal de Strauss e Howe (1991) sobre os processos de mudança social em amplo estudo da história anglo-americana recupera a atenção dos estudos sociais acerca das gerações, enquanto propõe que cada geração define a natureza momentânea do estágio do ciclo de vida em que se encontra. À medida que cada geração passa para outro estágio do ciclo de vida, ocorre uma reviravolta (turning), isto é, o comportamento e as atitudes das fases do ciclo mudam inteiramente de caráter. Esse conceito - turning -, mais elaborado em outro trabalho (STRAUSS e HOWE, 1997), sob o rótulo The Fourth Turning ou Quarta Reviravolta, mostra um alto grau de pertinência com a crise atual e o futuro de suas conseqüências. Embora crises aconteçam ao longo da História, elas muitas vezes não encontram a concentração de grupos geracionais que propicie uma "quebra de civilizações". Mas tal condição existe na Quarta Reviravolta. É como se fosse a crise moldando as gerações e a combinação de gerações moldando a crise - tudo trabalhando para criar uma nova sociedade e um novo código de valores.

Para melhor compreender os fenômenos geracionais, dois conceitos merecem atenção: o conceito de memórias coletivas e o conceito de coortes históricos. Enquanto o conceito de 
memórias coletivas afirma que indivíduos com idades similares têm memórias similares quanto a eventos históricos, o conceito de coorte histórico afiança que há, nas pessoas, um período onde a intensidade da formação de valores é maior e que a assimilação desses valores agrupa as pessoas em torno dessa similaridade. Assim, ambos contabilizam a formação de valores.

O importante das memórias coletivas reside no fato de que quando as pessoas experimentam um fenômeno social, particularmente durante o fim de sua adolescência ou o começo da fase adulta - período formativo -, elas o citam com muito mais freqüência e tendem a atribuir razões pessoais para fazê-lo (SCHUMAN e SCOTT, 1989). Assim, por exemplo, pessoas em cada um dos três coortes holandeses (nascidos antes de 1945, entre 1945 e 1964 e depois de 1964) referiram-se quase sempre ao mesmo evento quando perguntadas sobre aquele que teria sido o mais importante para o século $\mathrm{XX}$, mas a interpretação e a atribuição de significados aos eventos foi claramente diferente em função das experiências desses indivíduos durante seus anos formativos (ESTER, VINKEN e DIEPSTRATEN, 2000). Em outro estudo (SCHUMAN e CORNING, 2006), que compara a Guerra do Iraque à Guerra do Vietnam e à II Guerra Mundial, entrevistados que viveram durante a Guerra do Vietnam tendiam a citá-la mais freqüentemente do que citavam a II Guerra Mundial. Em estudo semelhante, Scott e Zac (1993) pediam aos entrevistados que pensassem sobre eventos relacionados a mudanças nacionais ou internacionais dos 60 anos que antecederam a pesquisa e que citassem um ou dois que considerassem especialmente importantes.

Respondentes mais jovens, do coorte da Guerra do Vietnam, que citaram essa guerra com mais freqüência, tendiam a considerar a II Guerra como a "guerra boa", na qual americanos lutaram para derrotar o mal. Para esses indivíduos, a II Guerra foi um evento que ocorreu antes do seu período formativo. Essa visão é uma "representação coletiva" da II Guerra, conceito diferente de "memória coletiva". Na memória coletiva, a diferença se dá menos por causa da memorização, porém, por sentimentos pessoais que acompanham os eventos vividos. Na representação coletiva, os indivíduos mais jovens tomam conhecimento do evento através de depoimentos de outras pessoas, enquanto os mais velhos têm a memória coletiva de uma experiência direta e concreta em relação ao evento.

Por sua vez, o conceito de coorte vai mais adiante, pois afirma que nesse mesmo período, normalmente entre o fim da adolescência e o início da fase adulta, as experiências compartilhadas de vida levam à fixação de valores que, permanecendo pelo resto das vidas das pessoas, criam um vínculo entre elas formando, então, um coorte (MEREDITH, SCHEWE e KARLOVICH, 2001).

Desse modo, os valores fixados, normalmente ligados a atitudes e preferências, costumam resistir às mudanças de idade e às fases do ciclo de vida pessoal (NOBLE e SCHEWE, 2003). No entanto, em decorrência de sua localização histórica, um coorte, por ter sido socializado em período de tempo distinto, difere de seu antecessor. Com efeito, se um coorte tende a contestar o anterior em seus valores, essa contestação torna-se, então, uma força geradora de mudanças sociais (GLENN, 2005). Ora, se valores fixados permanentemente nos indivíduos os fazem reagir de maneira distinta (MEREDITH et al, 2002), eles provêem uma forma alternativa de olhar futuros comportamentos sociais e hábitos de consumo, de acordo com os valores assimilados em diferentes momentos históricos.

Supõe-se legitimamente, então, que a assimilação de valores, via coortes, atribui ao conceito de geração um significado robusto e diferente dos meros anos de nascimento. Enquanto momentos históricos definem coortes, o período compreendido entre a data de nascimento e 
a idade reprodutiva de uma pessoa é que define, trivialmente, o conceito de geração. A origem do conceito de coortes chamou a atenção para o fato de que eventos de uma sociedade determinam os coortes, enquanto as datas biológicas determinam as gerações (MANNHEIM, 1928). Desse modo, o conceito de coorte difere do conceito popular de gerações (ROGLER, 2002) porque classifica gerações por momentos históricos e não por meros períodos de vida. Momentos históricos importantes compreendem cataclismos sociais, restaurações religiosas, convulsões econômicas e outras mudanças repentinas que acontecem em determinados períodos históricos.

Uma crise econômica de grandes repercussões que constitui um momento histórico recebe o título de momento definidor de um novo coorte, quando abre as portas para uma nova transformação geracional. Assim, momentos definidores germinam coortes, sendo que cada coorte perdura até o aparecimento de um novo momento definidor. Por sua vez, os momentos definidores carregam em si uma coleção de características em virtude de sua natureza e localização histórica. Um novo momento definidor traz uma nova coleção que discrepa da anterior, produzindo, por conseqüência, um coorte moldado em uma composição própria, tal como um caráter que o identifica entre os demais (RYDER, 1965).

\section{PREMISSA DA CRISE}

Há menos dúvidas sobre a existência da crise atual do que sobre sua extensão e gravidade. Krugman (2009), buscando entender a crise atual, coteja outras crises e lembra o pensamento keynesiano de ação governamental que se recupera na época presente. Mas entender uma crise de grande repercussão e profundidade parece tarefa tão difícil quanto provocativa. Galbraith (1955) salienta, ao concluir sua conhecida análise sobre a Grande Depressão, que entender os desdobramentos de uma depressão exige mais conhecimentos do que simplesmente explicar as quedas no mercado de ações. Ainda se segue o caminho mais fácil, quando prevalece o esforço de explicar com raciocínios mais acessíveis os problemas dos mercados financeiros. Baker (2009), por exemplo, estuda o estouro das bolhas em tempos recentes e conclui que, embora elas possam ser previstas, acabam sendo ignoradas. Kansas (2009) analisa o emaranhado do sistema financeiro, mostrando que a complexidade dos sistemas de crédito esconde os riscos envolvidos.

Woods Jr. (2009), com extrema objetividade, atira para o governo a responsabilidade pelos ciclos econômicos. Nesse meio, porém, alguns trabalhos recuperam a análise da depressão via estudo das gerações. Gronbach (2008) alia sua proposta com a de trabalhos anteriores (DENT, 1998) e alerta que se uma geração com população menor substitui uma geração com população maior haverá impacto sobre a oferta e a demanda. Dent (2009) faz um alerta no mesmo sentido, ao afirmar que uma geração nascente menor não pode sustentar o mesmo nível de consumo da geração precedente. E propõe uma análise via ciclos geracionais em quatro fases A Quarta Reviravolta guarda semelhança com as quatro fases propostas por Dent: inovação, crescimento, shakeout e maturidade. A inovação é a fase da invenção, na qual os jovens impulsionam as novas tecnologias. $\mathrm{Na}$ fase de crescimento, acontece a experimentação, quando a adoção das novas tecnologias, que se inicia com $10 \%$ da população, se conclui com cerca de $90 \%$ desta. Depois, vem o shakeout - a depressão ou descarte quando se definem os melhores, ou os únicos que sobreviverão. Finalmente, chega-se à maturidade - a fase mais tranqüila -, quando há verdadeiramente a melhoria da qualidade de vida. Desse modo, acompanhando os ciclos históricos com base em ciclos econômicos, demográficos e tecnológicos, Dent (2009) posiciona o momento atual na terceira fase shakeout -, que durará até a segunda década do século atual, quando se acredita que o mundo 
viverá uma fase de bonança. Justifica essa proposta observando que uma geração atinge o pico de seus gastos de consumo entre 40 e um pouco mais de 50 anos de idade, tendo seu pico perto de 49 anos.

Uma vez que a grande maioria dos Baby Boomers (nascidos entre 1946 e 1964) se aposenta nos momentos atuais, ele prevê uma forte queda de demanda geral e do mercado de ações. Os Baby Boomers são uma geração numerosa e seus movimentos têm grande impacto na economia e nos valores vigentes. Dent (2009) afirma que muitos deles, nos próximos anos, terão que se desfazer de seus investimentos em ações para repor seus salários, provocando uma grande queda no valor das ações. Assim, como também inexiste substituto de igual magnitude para os Baby Boomers, conjectura que o mundo está prestes a enfrentar a pior crise já vivida no último século, prevendo seu período crítico para entre 2010 e 2014.

Tal como Strauss e Howe (1997), Dent (2009) fala da conjugação de vários ciclos, sendo que o tempo presente iguala-se a uma "Tempestade Perfeita", quando vários ciclos se encontram na entrada da fase de depressão. Por seu turno, Strauss and Howe (1997) falam de uma conjugação de valores, ou seja, de uma "combinação perfeita de gerações", que gera a Quarta Reviravolta - na qual, apesar da queda da ordem social, a demanda de uma nova ordem cresce. Mas, tanto uma análise quanto a outra, prevêem, para após a crise, uma era de melhor qualidade. Enquanto Dent (2009) vê um período de maturidade após o shakeout, Strauss e Howe (1997) vêem uma reestruturação social maior. 0 caminho da Quarta Reviravolta se pauta por uma trajetória que se inicia na crise e vai até o despertar para uma civilização melhor. Inclui, no início, aspectos negativos como: crise fiscal, impasse orçamentário, medo, falta de confiança, individualismo, decadência institucional, pessimismo, governo que não cumpre promessas, idosos sem poupança ou ganhando menos e desemprego entre os jovens. Mas inclui, para mais adiante, aspectos positivos, como novas lideranças, eficiência e produtividade, vida simplificada, menos liberdade individual, trabalho em equipe, disposição a sacrifícios, sociedade mais igualitária, renascimento da confiança.

Strauss e Howe (1997) previram o início da grande crise para entre os anos 2006 e 2010, enquanto Dent (2009) previu o início entre os anos 2010 e 2014. Embora haja coincidência significativa nas datas, ambos observaram ciclos de cerca de 80 anos para suas conclusões. No entanto, ao passo que Strauss e Howe (1997) se valeram de informações históricas, Dent (2009) se valeu de correlações entre dados demográficos e econômicos. Provocativa, ainda, é a previsão feita em 1925 pelo conhecido economista russo Kondratieff da ocorrência de uma grande depressão global para 2010 (VAN DUIJN, 1983).

\section{COORTES NO BRASIL E A GERAÇÃO NASCENTE}

A identificação de coortes ajuda a entender tanto a localização histórica dos momentos definidores quanto os valores associados a cada coorte. Embora a formação de coortes por valores de consumo tenha sido amplamente estudada no Brasil, por exemplo, em música (KITAJIMA e MOTTA, 2005) e astros de TV (RUBENS e MOTTA, 2005), faltam estudos sobre o fenômeno das memórias coletivas similares àqueles encontrados nos Estados Unidos e em outros países. Apesar disso, coortes históricos definidos para o Brasil mostram suas características distintivas (MEREDITH, SCHEWE e KARLOVICH, 2001; MOTTA, ROSSI e SCHEWE, 2002) e auxiliam a suprir essa carência.

\section{MÉTODO}

Coerentemente, a fim de subsidiar o delineamento de um novo coorte histórico para o Brasil, 
o método utilizado nessa investigação compõe-se de dois estudos distintos. 0 primeiro estudo explora a validade das memórias coletivas brasileiras em relação a eventos históricos, a partir de estudos publicados acerca de definições de coortes históricos. Desse modo, ao se estabelecer a existência do fenômeno de memórias coletivas, estabelece-se, por conseqüência, sustentabilidade maior para os valores do coorte nascente. 0 segundo estudo levanta a estrutura analítica para ancorar a formulação de um novo coorte geracional. Ambos estudos e seus respectivos resultados são descritos a seguir.

\section{ESTUDO 1}

O primeiro estudo parte dos coortes históricos já definidos para o Brasil (MEREDITH, SCHEWE e KARLOVICH, 2001; MOTTA, ROSSI e SCHEWE, 2002) como meio de entender tanto a localização histórica dos momentos definidores, quanto os valores associados a cada coorte, conforme a breve descrição a seguir.

Coorte I - A Era Vargas (nascidos entre 1913 e 1928, período formativo entre 1930 e 1945): 0 nome desse coorte se inspira em Getúlio Vargas, líder carismático que governou o país com mãos de ferro entre dois golpes de estado e duas Constituições. Em função de propaganda insistente e tendenciosa, sempre com o objetivo de autopromoção e exaltação de valores nacionais, os indivíduos desse coorte desenvolveram um forte culto ao nacionalismo, bem como a percepção de que o Estado seria a solução para todas as questões nacionais. Em geral, as pessoas pertencentes a esse coorte são conservadoras, religiosas, simples e caseiras.

Coorte II - Pós Guerra (nascidos entre 1929 e 1937, período formativo entre 1946 e 1954): Uma forte onda de moralismo varreu o país nesse período e família, igreja e casamento eram as instituições mais valorizadas. Divórcio e jogo eram proibidos, sob a alegação de que a tradição moral, jurídica e religiosa da nação era contra estas práticas. A volta ao liberalismo e o nascente desejo por consumo de bens levou o "ter" a prevalecer o "ser". Três atributos melhor descrevem as pessoas desse coorte hoje: bondade, hospitalidade e sentimentalismo.

Coorte III - Otimismo (nascidos entre 1938 e 1950, período formativo entre 1955 e 1967): Diferentes cenários que se uniram pela esperança e crença de que o Brasil era o "país do futuro"

formaram esse coorte com características fascinantes, tais como uma liberdade política sem precedentes, maiores salários, rápida industrialização e um clima de euforia. A classe média identificou-se com a juventude e a orientação liberal do então presidente da república que, por sua vez, tirando vantagem do sentimento de nacionalismo crescente, introduziu a noção de sacrifício. Em resumo, este coorte testemunhou a transformação do conceito de democracia no conceito de rejeição radical à desordem. Por conseguinte, seus principais valores são: otimismo, aversão à desordem e aceitação de sacrifício.

Coorte IV - Os Anos de Ferro (nascidos entre 1951 e 1962, período formativo entre 1967 e 1979): Esse coorte viveu durante um regime militar ditatorial repressivo no qual os direitos civis foram significativamente restringidos, a censura instituída e a oposição política banida. Levar vantagem sobre os outros era louvado como virtude na TV. A harmonia dos relacionamentos interpessoais foi definitivamente rompida, à medida que cautela, desconfiança e cinismo tornaram-se, para a maior parte das pessoas, substitutos das relações genuínas, cândidas e honestas entre as pessoas.

Coorte V - A Década Perdida (nascidos entre 1963 e 1974, período formativo entre 1980 e 1991): Apesar de ter aproveitado uma atmosfera sem censura nessa década, o país estava em 
um período de insegurança. Pessoas desse coorte sentiam-se frustradas com o fracasso dos planos econômicos, elaborados para controlar a inflação monetária. Elas também encararam o materialismo e o individualismo da cultura de massa ocidental contemporânea. A maioria das pessoas deste coorte sentiu-se sem esperança, sem confiança nas classes política e empresarial e tinham pouca fé nas iniciativas governamentais.

Coorte VI - Cada Um Por Si (nascidos a partir de 1975, período formativo a partir de 1992): As características principais desse coorte são o consumismo, a tentativa de recuperar os valores éticos e morais e o movimento no sentido da globalização. As pessoas deste coorte também enfrentaram um período que, economicamente, pode ser caracterizado por altas taxas de desemprego e a privatização, ambos os fenômenos sujeitos a fortes críticas. 0 sentimento de ser cada um por si foi parcialmente criado pela mistura de promessas e incertezas sobre 0 futuro do país e, em parte, pela novidade do shopping center e da vida digital. Como riqueza significa poder social e/ou político, para eles a realização de gastos era uma prática geralmente aceitável.

O Estudo 1 foi conduzido junto aos três coortes mais recentes - pessoas nascidas entre 1951 e 1981, brevemente descritos acima - envolvendo uma pesquisa precedida por uma série de entrevistas qualitativas para determinar eventos importantes. A pesquisa incluiu brasileiros que pertenciam às classes $\mathrm{A} e \mathrm{~B}, \mathrm{o}$ que tem embasamento na forte desigualdade econômica no país, responsável pela exclusão de boa parte da população na participação e entendimento da maioria dos eventos econômicos. Estudos anteriores (SCHUMAN e SCOTT, 1989) comprovam que somente os grupos mais diretamente envolvidos com essas mudanças demonstram a formação de memórias coletivas. Após essa fase, desenvolveu-se um breve instrumento de teste. Assim, os pesquisadores distribuíram 800 questionários através de uma amostra por conveniência. Desses, retornaram, 769. Em função da dificuldade de pré-detectar a classe social, foram descartados 76, cujos respondentes pertenciam à outra classe social. Além desses, foram descartados outros 121 questionários por causa de erros nas respostas. A amostra final contou com 572 questionários válidos para análise dos seguintes coortes: 202 do coorte IV (nascidos entre 1951 e 1962), 179 do coorte V (nascidos entre 1963 e 1974) e 191 do coorte VI (nascidos entre 1975 e 1981). Com relação a gênero, 300 respondentes eram homens e 272 mulheres. Em função da maioria dos membros dos primeiros três coortes estarem com mais de 70 anos, eles não foram incluídos na amostra. Solicitou-se aos respondentes que escolhessem três entre dezesseis eventos, de acordo com o seguinte critério: eventos que os fizeram refletir mais ou tiveram o maior impacto em suas vidas. Havia, também, espaço para incluir outros eventos que o respondente considerasse relevantes.

A Tabela 1 mostra o resumo dos resultados encontrados. Como previsto, membros do coorte IV (nascidos entre 1951 e 1962) citaram o fim da ditadura militar e a volta à democracia como eventos definidores. Membros do coorte V (nascidos entre 1963 e 1974) citaram a morte do Presidente Tancredo Neves, o impeachment do Presidente Collor e o primeiro presidente eleito de forma direta em muitas décadas como eventos definidores. Finalmente, membros do coorte VI citaram o plano real, que introduziu uma nova moeda e deu fim à inflação que durou mais de quatro décadas, e o advento da internet como eventos definidores.

Na verdade, a formação de um coorte é conseqüência de uma alteração no modo de vida em um determinado momento, alteração essa causada por um evento definidor. Um evento é considerado definidor justamente quando gera conseqüências sociais que afetarão os membros de um coorte. 
Portanto, eventos como uma crise, uma guerra ou mesmo uma reestruturação econômica podem gerar uma série de outros eventos que, em conjunto, provocarão alterações profundas no modo de vida da sociedade e marcarão de forma definitiva as pessoas que estiverem em seu período de formação.

Tabela 1: Resumo dos Resultados - Memórias Coletivas no Brasil

\begin{tabular}{|l|c|c|c|}
\hline & $\begin{array}{c}\text { Coorte IV: } \\
\text { Os Anos de Ferro. } \\
\text { Período formativo } \\
\text { entre 1967e } \\
1979 .\end{array}$ & $\begin{array}{c}\text { Coorte V: } \\
\text { A Década Perdida. } \\
\text { Período formativo } \\
\text { entre 1980 e 1991. }\end{array}$ & $\begin{array}{c}\text { Coorte VI: } \\
\text { Cada Um Por Si. } \\
\text { Período formativo a } \\
\text { partir de 1992 }\end{array}$ \\
\hline Ato Institucional N 5 - AI5 (1968) & $\mathbf{5 1 \%}$ & $30 \%$ & $19 \%$ \\
\hline Crise do Petróleo de 1979 & $\mathbf{4 4 \%}$ & $25 \%$ & $31 \%$ \\
\hline Fim do Regime Militar & $\mathbf{5 7 \%}$ & $21 \%$ & $22 \%$ \\
\hline Movimento das Diretas Já (1983-84) & $\mathbf{4 1 \%}$ & $\mathbf{4 1 \%}$ & $18 \%$ \\
\hline Morte de Tancredo Neves (1985) & $44 \%$ & $\mathbf{4 3 \%}$ & $13 \%$ \\
\hline Criação da internet (1990) & $28 \%$ & $29 \%$ & $\mathbf{4 3 \%}$ \\
\hline Impeachment de Collor (1992) & $27 \%$ & $35 \%$ & $\mathbf{3 8 \%}$ \\
\hline Criação do telefone celular (1995) & $28 \%$ & $30 \%$ & $\mathbf{4 2 \%}$ \\
\hline Desvalorização do real (1999) & $23 \%$ & $34 \%$ & $\mathbf{4 3 \%}$ \\
\hline Eleição do Presidente Lula (2002) & $28 \%$ & $32 \%$ & $\mathbf{4 0 \%}$ \\
\hline
\end{tabular}

Os dados em negrito são esperados como os de maior valor

Como esperado, com base na teoria de memórias coletivas, a freqüência de eventos citados está relacionada ao período formativo do respondente. Com exceção do quinto coorte, cuja escolha de eventos se confunde com a do quarto, os outros dois em estudo (coorte IV e VI) confirmam a teoria das memórias coletivas, citando eventos relacionados ao seu período formativo com freqüência claramente maior que os demais; ou seja, eventos que aconteceram quando os coortes IV e VI estavam em seu período de formação são lembrados mais freqüentemente por esses grupos. Portanto, é apropriado assumir que associações similares serão possíveis com os eventos definidores que constituem o momento histórico que irá produzir o novo coorte.

\section{ESTUDO 2}

Este estudo contabiliza, essencialmente, as experiências negativas do ambiente atual, conforme expectativas da Quarta Reviravolta, que identificam os possíveis valores a serem compartilhados no período formativo e os sintetiza em valor fixado para a vida toda.

Pela conexão analítica entre as experiências negativas no ambiente atual e os valores supostamente compartilhados pela geração nascente, procura encontrar uma síntese para os valores analisados. Houve preocupação em limitar o número das experiências negativas quanto aos valores compartilhados, em virtude da dificuldade de se detalhar excessivamente um coorte que se encontra em fase de formação. Desse modo, dentre valores obtidos das fontes citadas, somente aqueles que puderam ser cotejados e reconhecidos em um número expressivo de artigos de jornais e revistas sobre a crise atual foram considerados.

Obteve-se, então, 14 principais experiências negativas, classificadas em quatro grupos, de acordo com a Tabela 2: 
Tabela 2: Classificação por Grupo das Experiências Negativas Relacionadas ao Novo Coorte

\begin{tabular}{|c|c|c|c|}
\hline $\begin{array}{c}\text { GRUPO 1 } \\
\text { AVERSÃO AO RISCO }\end{array}$ & $\begin{array}{c}\text { GRUPO 2 } \\
\text { PROTEÇÃO } \\
\text { GOVERNAMENTAL }\end{array}$ & $\begin{array}{c}\text { GRUPO 3 } \\
\text { RESTRIÇÃO DE } \\
\text { CONSUMO }\end{array}$ & $\begin{array}{c}\text { GRUPO } 4 \\
\text { SENSO DE PROPÓSITO }\end{array}$ \\
\hline Falência Corporativa & Recessão & Dívida Substancial & $\begin{array}{l}\text { Falta de Ética nos } \\
\text { Negócios }\end{array}$ \\
\hline Falência Individual & $\begin{array}{c}\text { Fracasso de Planos de } \\
\text { Pensão }\end{array}$ & $\begin{array}{l}\text { Consumo Anterior } \\
\text { Excessivo }\end{array}$ & $\begin{array}{c}\text { Falta de Ética no } \\
\text { Governo }\end{array}$ \\
\hline \multirow[t]{3}{*}{ Fracasso dos Bancos } & $\begin{array}{c}\text { Baixa Perspectiva de } \\
\text { Sucesso }\end{array}$ & Gasto Anterior Excessivo & $\begin{array}{c}\text { Falta de Conexões } \\
\text { Sociais }\end{array}$ \\
\hline & Perdas de Emprego & & \\
\hline & Desemprego Nacional & & \\
\hline
\end{tabular}

Aversão ao Risco . A aversão ao risco denomina o primeiro grupo, que reúne as experiências negativas com falências corporativas, falências individuais e fracassos bancários. Tal como a geração da Grande Depressão sentiu, a nova geração sente os efeitos das falências corporativas e dos fracassos bancários (GALBRAITH, 1997; KRUGMAN, 2009). Muitas pessoas percebem que esses efeitos decorrem dos elevados riscos assumidos porque, em virtude das baixas taxas de juros, muitos arriscaram mais do que podiam, imaginando que todas as probabilidades trabalhariam em seu favor. $\mathrm{O}$ que não tem acontecido. Na medida em que vêem outras pessoas também incorrendo em fracassos similares, em virtude de atitudes, de investimentos e de gastos desmedidos, incorporam valores de rejeição a essa situação, enquanto perduram suas esperanças por mudanças.

Fatalmente, considerando irracionais tais atitudes, passam a compartilhar valores como sentir perigo nos investimentos, reprovar endividamentos, temer inovações e precaver-se nos empreendimentos. Para aqueles que se encontram em seus anos formativos, o atraso na recuperação da economia se apresenta como uma premissa revoltante, embora possível. Assim, a velocidade do progresso que desejam se reduz, por conseqüência desta sua própria aversão ao risco, prevalente na geração da época da Grande Depressão, quando também se retardou a recuperação da economia americana (DENT, 2009).

Sem dúvida, é um comportamento paradoxal, já que a introjeção de novos valores evitaria uma desnecessária extensão da recessão.

Proteção Governamental. A proteção governamental sintetiza a reunião de experiências negativas com recessão, desemprego nacional, fracasso dos fundos de pensão, perda de emprego e baixa perspectiva de sucesso.

No período de recessão, a freqüência em que os dados da crise são publicados aumenta. Mas também aumenta a freqüência com que alguns dados mudam de rumo. Esta alternância, observada também durante a Grande Depressão, cria um ambiente de elevada desconfiança que se traduz, para a geração nascente, em baixa perspectiva de sucesso. Além da divulgação prioritária dos índices de queda de produção e aumento de desemprego, as pessoas vivenciam proximamente a perda de emprego, o prejuízo dos investimentos e as perdas em fundos de pensão.

Uma pesquisa recente conduzida por The Pew Research Center for the People \& the Press (2007) revela que mais de $50 \%$ de pessoas acima de 30 anos perderam mais de $20 \%$ de seus fundos de pensão. Na outra ponta, as expectativas quanto à recuperação da economia são bem mais elevadas entre os jovens. 0 olhar para o passado mostra que, no começo, a recessão não 
destrói totalmente as esperanças; mas com o passar do tempo, os mais jovens começam a sentir que as perspectivas de sucesso enfraquecem, gerando forte sentimento de desproteção. Vendo as ofertas de emprego se reduzir e seus pais perderem renda imediata e futura, a geração nascente busca alternativas. Essas normalmente excluem a ambição de ser independente e de contar consigo mesmo para a sobrevivência. Na verdade, enquanto essa ambição enfraquece, a demanda por maior proteção governamental cresce.

Ao passar por dificuldades, a inclinação ao sacrifício emerge como uma hipótese plausível. Sentindo-se inclinada a sacrificar interesses pessoais em favor do país, da família, de sua religião ou seu trabalho, essa nova geração se iguala à motivação do coorte da Grande Depressão americana ao dar maior valor à comunidade e à família (MEREDITH, SCHEWE e KARLOVICH, 2001). Na verdade, somente pessoas que cresceram em uma sociedade com alta noção de comunidade podem vir a ter uma real compreensão do tema. Essa possibilidade cresce na medida em que cresce nos Estados Unidos o número de jovens que voltam para a casa dos pais e de outros parentes para dividir o mesmo teto (THE PEW RESEARCH CENTER FOR THE PEOPLE \& THE PRESS, 2007). Coerentemente, passam a pensar na união de forças para atingir objetivos sociais, de forma semelhante aos membros dos coortes da II Guerra Mundial, tanto no Brasil como nos Estados Unidos. No entanto, se, por um lado, essa nova geração recupera valores, por outro, aprende a culpar a geração anterior pela diminuição da harmonia nas relações interpessoais, na comunidade e na vida familiar.

Em suma, percebem continuamente que será necessário, para sobreviver, olhar para o Estado como uma solução dos problemas econômicos e sociais, já que terão dificuldade em contar com apoio financeiro familiar.

Restrição de Consumo. A restrição de consumo rotula o valor a ser fixado para a vida toda, congregando experiências negativas com dívidas substanciais e consumo e gastos excessivos efetuados pela geração anterior. Na perspectiva em que terá que suportar as conseqüências desses gastos de consumo excessivos, o coorte nascente questionará veementemente o significado de "viver acima das próprias possibilidades". Autodisciplina no consumo, que parecia um argumento ilógico para a geração que vivenciou uma longa fase de crescimento econômico e de crédito fácil, encontra agora terreno fértil, tendendo mesmo para adoção de restrições. Assim, no atual ambiente econômico, os esforços para aumentar o consumo sofrerão resistência dos membros da nova geração. Possuídos de uma consciência em relação aos gastos, poderão demonstrar um desdém por marcas de luxo e uma propensão a viver com os próprios meios.

Valores como desempenho, ambição, riqueza, materialismo, sucesso e competitividade, como definidos por Hofstede (2003), não devem prevalecer sobre valores como qualidade de vida, relacionamentos pessoais mais próximos, solidariedade, igualdade, preservação ambiental e preocupação com o próximo (HOFSTEDE, 1980, 1991, 1994).

Senso de Propósito. Finalmente, o senso de propósito reúne as experiências negativas de falta de ética nos negócios e no governo, bem como a ausência de conexões sociais. 0 sentimento de ter sido ludibriado pela geração anterior fará o coorte nascente demandar um novo código, baseado em honestidade e integridade. No Brasil, o coorte II (Pós Guerra), após a longa ditadura da Era Vargas, buscou uma vida pautada pela ética e religiosidade, embora o mesmo não tenha acontecido após a queda do regime militar, com o coorte IV (MEREDITH, SCHEWE e KARLOVICH, 2001). Os esforços de recuperação ética só ressurgiram no coorte VI, após o impeachment do Presidente Collor. 
Nascendo em meio a uma abundância de carência de ética, tanto no comportamento das empresas quanto dos governos, a geração emergente terá que reinventar vários conceitos. Poderá, por exemplo, reinventar o significado do trabalho. Se o desemprego permanecer por um período mais longo, o trabalho por si só será o tema. Poderá, também, ir além e tentar reinventar o mundo que a cerca, até em busca de uma nova civilização, conforme suscitado pela quarta reviravolta. Ao vivenciar escassas possibilidades de sucesso, o novo coorte poderá, também, questionar a forma displicente como foram tratados, no passado, temas mais sensíveis à ética, da mesma forma como rejeitará a cultura individualista. Roth (1995) argumenta que, em culturas individualistas, as pessoas tendem a desrespeitar regras sociais e a tomar decisões de forma independente. Na contramão desse tipo de atitude, a geração emergente deverá partir em busca de uma cultura coletivista, em que pessoas vivem sob acordos coletivos e favorecem a lealdade aos grupos a que pertencem. A contrapartida que segue, segundo Kagitcibasi (1997) é a busca de maior proteção por parte desses grupos.

Por fim, em termos de estilo de vida, a importância do "ser" deve ultrapassar a do "ter", tão perseguido pelas gerações imediatamente anteriores. 0 objetivo desse novo grupo tenderá a ser levar uma vida de maior simplicidade, onde o mais valorizado serão os relacionamentos interpessoais. É um novo senso de propósito.

Tabela 3: Comportamentos do Novo Coorte Potencial

\begin{tabular}{|c|c|c|}
\hline $\begin{array}{c}\text { EXPERIÊNCIAS NEGATIVAS } \\
\text { NO AMBIENTE ATUAL }\end{array}$ & $\begin{array}{c}\text { VALORES COMPARTILHADOS } \\
\text { DA GERAÇĀO EM } \\
\text { CRESCIMENTO }\end{array}$ & $\begin{array}{l}\text { VALORES FIXADOS } \\
\text { PARA A VIDA }\end{array}$ \\
\hline $\begin{array}{l}\text {-Falências Corporativas } \\
\text {-Falências Individuais } \\
\text {-Fracassos Bancários }\end{array}$ & $\begin{array}{l}\text {-Investir é perigoso } \\
\text {-Endividamento é reprovável } \\
\text {-Medo de inovação } \\
\text {-Precaução no empreendedorismo }\end{array}$ & AVERSÃO AO RISCO \\
\hline $\begin{array}{l}\text {-Recessão } \\
\text {-Fracassos dos Planos de Pensão } \\
\text {-Baixa Perspectiva de Sucesso } \\
\text {-Perdas de Empregos } \\
\text {-Desemprego Nacional }\end{array}$ & $\begin{array}{l}\text {-Sentimento de desproteção } \\
\text {-Maior valor para comunidade / família } \\
\text {-Soluções governamentais } \\
\text {-Cooperação do grupo / time }\end{array}$ & $\begin{array}{c}\text { PROTEÇÃO } \\
\text { GOVERNAMENTAL }\end{array}$ \\
\hline $\begin{array}{l}\text {-Dívida Substancial } \\
\text {-Consumo Anterior Excessivo } \\
\text {-Gastos Anteriores Excessivos }\end{array}$ & $\begin{array}{l}\text {-Restrições de consumo } \\
\text {-Desdém por marcas de luxo } \\
\text {-Maior consciência em relação a gastos } \\
\text {-Viver com os próprios meios }\end{array}$ & CONSUMO RESTRITO \\
\hline $\begin{array}{l}\text {-Falta de Ética nos Negócios } \\
\text {-Falta de Ética no Governo } \\
\text {-Falta de Conexões Sociais }\end{array}$ & $\begin{array}{l}\text {-Significado do trabalho } \\
\text {-Integridade e honestidade } \\
\text {-Rejeição do individualismo } \\
\text {-Simplicidade na vida }\end{array}$ & SENSO DE PROPÓSITO \\
\hline
\end{tabular}

\section{DISCUSSÃO E CONCLUSÃO}

A proposta acima supõe que a nova geração se incorpore à trajetória da Quarta Reviravolta, prevista para épocas atuais. Twenge (2006) já apontou algumas dificuldades a serem enfrentadas pela geração mais recente. Segundo suas pesquisas, trata-se de uma geração de crianças desejadas, protegidas, estimuladas, acostumadas a ter sua opinião sempre considerada e que cresceram acreditando que buscar um sonho era a certeza da felicidade. Ao encontrar a realidade financeira que se desenha, sofrerão enorme decepção. E a "quebra de civilizações" prevista pela Quarta Reviravolta representará um período de ainda maiores privações e dificuldades que o atual, ilustrado no estudo de Twenge (2006). Essa geração tenderá, então, a culpar as gerações anteriores pelas dificuldades que terá que enfrentar e a criar seu próprio código de valores, destoante do código usado por seus antepassados 
recentes.

Para além dessas análises, a literatura pertinente sugere, entre outros rótulos, para as gerações mais recentes: Geração X (Xers) e Geração Y (Yers), que sucederam a geração dos Baby Boomers (TULGAN, 2009; GORDINIER, 2008). Os Xers, nascidos entre 1966 e 1976 (MEREDITH, SCHEWE e KARLOVICH, 2001), têm menor expressão quantitativa. São a geração "espremida" entre os Baby Boomers e a Geração Y. Na verdade, as divergências entre gerações não é surpresa nem exclusividade da geração a caminho. Gullete (2004) discute como os Xers, ao atingir a maturidade, chocaram-se com os Boomers, que usufruíam dos melhores empregos e melhores salários. Ao encontrar dificuldades para se destacar, os Xers questionaram os Boomers, reagindo ao que entendiam como uma "hierarquia de idades" em detrimento de outros méritos. Introduziram, então, uma nova forma de conduzir a própria carreira, buscando oportunidades onde fosse possível, ao invés de desejar estabilidade em um emprego vitalício.

Meredith, Schewe e Karlovich (2001) identificam a geração seguinte aos Xers como Geração $\mathrm{N}$, ao invés de chamá-la de Geração Y. O nome foi atribuído a esse coorte por causa de sua relação com a internet, fazendo dele a Net Generation. Há, portanto, diferentes definições para o coorte posterior aos Xers, embora seu nome mais freqüente seja Geração Y. Importante para atenção analítica será o esforço da geração nascente para sepultar os valores das gerações que a precederam em períodos mais recentes, como os Baby Boomers, os Xers e os Yers. Obrigada a se formar dentro da lacuna de gastos deixada pelos Baby Boomers, essa geração nascente entrará na vida adulta enfrentando um ambiente de possíveis conflitos geracionais.

Sentindo-se como vítimas de uma ditadura do consumo, ela se verá condenada a receber uma herança injusta, sendo improvável que esse novo coorte busque reconciliação com a geração anterior. Já na vida adulta, ela descobrirá que seu futuro foi vendido.

Acredita-se que não há motivo para que essas premissas não sejam válidas para o Brasil. A crise vem mostrando sinais pelo mundo, inclusive no Brasil. No que diz respeito aos coortes, os brasileiros, assim como os do resto do mundo, estão ficando cada vez mais parecidos, não só com os americanos, como entre si - efeito da globalização e da informatização, principalmente da internet (MEREDITH, SCHEWE e KARLOVICH, 2001). Portanto, supor que a nova geração brasileira será afetada pela crise e pela Quarta Reviravolta é plausível.

Não obstante, vaticinar sobre a era pós-depressão pode gerar uma perspectiva alentadora. Supõese que o consumo coletivo será apreciado, como resultado inevitável da contestação do comportamento individualista e egoísta das gerações precedentes. Um estilo de vida mais simples estimulará a redução do espaço dedicado a marcas e produtos de luxo. Produtos pessoais que estimulam o individualismo em detrimento do consumo familiar e coletivo serão negligenciados.

Os valores que se associam à forte conexão a ser resgatada entre amigos e família estarão, agora, afetando as decisões de consumo. Nesse meio, aflorará o sentimento de substituição do prazer material pelo de maior contato humano. E, eventualmente, serão acentuadas as tradições morais e familiares. Poderá haver uma recuperação da cultura do "ser" em detrimento da cultura do "ter".

Finalmente, para o mundo gerencial, o novo coorte histórico demandará novos padrões morais, o que significa não apenas propostas gerenciais responsáveis, mas práticas empresariais que compreendam a ética, a fim de obter reciprocidade no mercado. 


\section{REFERÊNCIAS}

BAKER, D. (2009). Plunder and Blunder. The Rise and Fall of the Bubble Economy. Sausalito, CA.

CUTLER, N. (1977). Political socialization Research as Generational Analysis: The Cohort Approach vs. the Lineage Approach. In Handbook of Political Socialization: Theory and Research, edited by Stanley Allen Renton. New York: Free Press.

DENT J.H.S. (1998). The Roaring 2000s: Building the Wealth and Lifestyle You Desire in the Greatest Boom in History. New York, Simon and Schuster.

. (2009). The Great Depression Ahead. New York: Free Press.

ESTER, P., VINKEN, H. e DIEPSTRATEN, I (2000). Collective Memories, Personal Biographies, and the New Millennium, Historical and Personal Correlates of Dutch People's Ideals and Anxieties for the 21st Century. Paper apresentado no 23rd Annual Scientific Meeting of the International Society for Political Psychology (ISPP), Seattle, WA (Julho): 1-4.

GALBRAITH, J.K. (1955). The Great Crash, 1929. New York, Mariner Books, edição de 1997. Boston.

GLENN, N.D. (2005). Cohort Analysis. Thousand Oaks, California, Sage Publications.

GORDINIER, J. (2008). X Saves The World: How Generation X Got The Shaft But Can Still Keep Everything From Sucking. Penguin Books Ltd, London, England.

GRONBACH, K.W. (2008). The Age Curve, How to Profit from the Coming Demographic Storm. New York, American Management Association.

GULlETTE, M.M. (2004). Aged by Culture. The University of Chicago Press, Chicago.

HOFSTEDE, G. (1980). Culture's Consequences: International Differences in WorkRelated Values. Beverly Hills, Sage Publications.

Hill.

. (1991). Cultures and Organizations: Software for the Mind. London, McGraw. (1994). Business Cultures. The UNESCO Courier. Vol. 30, n.4, (Abril), pp.

(2003). Culture's Consequences: Comparing Values, Behaviors, Institutions and Organizations across Nations. Sage Publications, Thousand Oaks, CA.

KAGITCIBASI, C. (1997). Individualism and Collectivism. In: Handbook of Cross Cultural Psychology, (Social Behavior and Applications, vol.3), 2nd ed. Berry, John W., Marshall h. Segall and Cigdem Kagitcibasi, eds. Boston, Allyn and Bacon: 1-49.

KANSAS, D. (2009). Guide to the End of Wall Street. New York.

KITAJIMA, I. e MOTTA, P.C. (2005). The Cohort Effect of Musical Taste. Proceedings, Balas Annual Conference, (Maio), Madrid.

KRUGMAN, P. (2009). The Return of Depression Economics and the Crisis of 2008. New 
York, W.W. Norton and Company.

MANNHEIM, K (1928). Das Problem der Generationen. Reimpresso em Essays on the Sociology of Knowledge. (1952). London: Routledge and Kegal Paul. 276-322.

MEREDITH, G., SCHEWE, C.D. e KARLOVICH, J. (2001). Defining Markets, Defining Moments. New York: Hungry Minds, Inc.

MEREDITH, G., SCHEWE, C.D., KARLOVICH, J. e HIAM, A (2002). Managing by Defining Moments. New York. Hungry Minds.

MOTTA, P.C., ROSSI, M.Z.G., e SCHEWE, C.D. (2002). Generational Marketing: Exploring Cohort-Programmed Values and Their Implications on Cross-cultural Variations in Consumer Behavior between Brazil and United States. Revista Portuguesa de Marketing, IPAM. Porto, 11-21.

MOTTA, P.C.; SCHEWE, C.D (2008). Are Marketing Management Decisions Shaped During One's Coming of Age? Management Decision. Vol. 46, n.7, pp. 1096-1110.

NOBLE, S.M.; SCHEWE, C.D. (2003). Cohort Segmentation: an Exploration of its Validity. Journal of Business Research. Vol. 56, pp. 979-87.

RENTZ, J.O., REYNOLDS, F.D. (1991). Forecasting the Effects of an Aging Population on Product Consumption: an Age-Period-Cohort Framework. Journal of Marketing Research. Vol. 28, n.3, pp. 355-60.

RENTZ, J.O., REYNOLDS, F.D. e STOUT, R.G. (1983). Analyzing Changing Consumption Patterns with Cohort Analysis. Journal of Marketing Research. Vol. 20, n.1, pp. 12-20.

RILEY, M.W. (1973). Aging and Cohort Succession: Interpretations and Misinterpretations. Public Opinion Quarterly. Vol. 37, Spring, pp. 35-49.

RODGERS, W.L. (1982). Estimable Functions of Age, Period, and Cohort Effects. American Sociological Review. Vol.47, n.6, pp. 774-87.

ROGLER, L.H (2002). Historical Generations and Psychology - The Case of the Great Depression and World War II. American Psychologist. Vol.57, n.12, pp. 1013-1023.

ROTH, M.S. (1995). The Effects of Culture and Socioeconomic on the Performance of Global Brand Image Strategies. Journal of Marketing Research. Vol.32 (Maio), pp. 163-175.

RUBENS, M. e MOTTA, P.C (2005). Exploratory Findings of Cohort Effects: Preferences for Cultural Products. In Delener, N. and Chao, C. (Eds), Readings Book, Global Business and Technological Association. Lisbon, pp. 1060-99.

RYDER, N.B. (1965). The Cohort as a Concept in the Study of Social Change. American Sociological Review. Vol.30, pp. 843-61.

SCHUMAN, H, e CORNING, A.D. (2006). Comparing Iraq to Vietnam - Recognition, Recall, and the Nature of Coorte Effects. Public Opinion Quarterly. Vol. 70, n.1 (Spring), pp. 78-87.

SCHUMAN, H, e SCOTT, J. (1989). Generations and Collective Memories. American Sociological Review. Vol. 54, (3): 359-81. 
SCOTT, J. e ZAC, L (1993). Collective Memories in Britain and the United States. Public Opinion Quarterly. Vol. 57, pp. 315-331.

STRAUSS, W. e HOWE, N. (1991). Generations: the History of America's Future, 1584 to 2069. William Morrow and Company Inc., New York, NY.

York, NY.

. (1997). The Fourth Turning: An American Prophecy. Broadway Books, New

THE ECONOMIST (2009). The Economist Newspaper Limited, London (June, 13th), capa.

THE PEW RESEARCH CENTER FOR THE PEOPLE \& THE PRESS (2007). A Portrait of Generation Next: How Young People View Their Lives, Futures and Politics. Disponível em <http://people-press.org/report/300/a-portrait-of-generation-next>, (January 9). Acesso em 31 de agosto de 2009.

TULGAN, B. (2009). Not Everyone Gets a Trophy: How to Manage Generation Y. JosseyBass - A Wiley Imprint, San Francisco, CA.

TWENGE, J.M. (2006). Generation Me. Free Press, New York, NY.

VAN DUIJN, J.J. (1983). The Long Wave in Economic Life. London: Allen \& Unwin.

WOODS JR., THOMAS E. (2009). Meltdown. Washington, Regnery Publishing, Inc. 